\title{
Complementary and alternative medicine use among patients with cancer in Mongolia: a National hospital survey
}

\author{
Buyadaa Oyunchimeg', Jung Hye Hwang ${ }^{1,2,3}$, Mansoor Ahmed ${ }^{2,4}$, Soojeung Choi ${ }^{1,2}$ and Dongwoon Han ${ }^{1,2,4,5^{*}}$ (D)
}

\begin{abstract}
Background: Complementary and alternative medicine (CAM) use is popular in former Soviet Central Asian countries including Mongolia. However, no studies are available on CAM use among patients with cancer in countries of this region. The aim of this research is to describe the prevalence and patterns of CAM use by patients with cancer in Mongolia.

Methods: A cross-sectional study was conducted using data from 482 cancer patients attending the National Cancer Center in Mongolia from September 2015 to February 2016. The survey instrument included 25 questions regarding CAM used, factors associated with use of CAM, cancer-related characteristics, and participants' socio-demographic profile.

Results: Among 482 respondents (response rate, 95.6\%), 47.9\% reported using one or more CAM modalities. Products of animal origin were the most popular modalities of CAM, followed by herbal products. Half of the users used CAM while receiving conventional treatment of cancer. Among users, only 29\% discussed the CAM use with their doctors. Female gender, younger age, higher education, shorter disease duration, and prior use of CAM were significantly associated with CAM use.

Conclusions: CAM appears to be widely accepted by patients with cancer in Mongolia. The findings support the urgent need for further in-depth study into commonly used oral CAM products and their potential effects on health of patients with cancer in Mongolia. High prevalence of CAM use among cancer patients in our study warrants further studies in other countries of Central Asia.
\end{abstract}

Keywords: Cancer, Complementary and alternative medicine, Conventional treatment, Predictors of CAM use, Mongolia

\section{Background}

The term complementary and alternative medicine (CAM) refers to a wide range of products and practices that are used outside of or alongside with conventional medicine. Globally, the use of CAM is particularly high and increasing among patients with cancer [1-9]. The most pressing concerns associated with such treatments are safety issues especially when they are used along with conventional medicine $[10,11]$. In addition, the lack of regulatory oversight raises serious concerns [12].

\footnotetext{
* Correspondence: dwhan@hanyang.ac.kr

'Department of Global Health and Development, Graduate school, Hanyang University, Seoul, South Korea

${ }^{2}$ Institute of Health Services Management, Hanyang University College of

Medicine, Seoul, South Korea

Full list of author information is available at the end of the article
}

In the countries of former Soviet Union including Mongolia, the prevalence of CAM use among general population ranges from 3.5 to $38 \%$ and many people use CAM for managing symptoms of chronic diseases [13, 14]. Moreover, immigrants from this region who live as ethnic minorities in the Middle East, East Asia and other countries have a high preference for using CAM approaches in several medical conditions $[15,16]$. The countries of this region have also one of the highest incidence rates of cancer in the world; however, no studies have focused on the CAM use among patients with cancer [17]. Hence, there is a need to conduct a focused study to provide information that might be useful in the practice, not only to local health professionals but also to the clinicians in those countries where Central Asians particularly Mongolians live as ethnic minorities. 
The purpose of this study was to determine the prevalence and patterns of CAM use, especially the specific CAM products used by cancer patients in Mongolia. The study also explored perceptions towards CAM use and predictors for using CAM and its use along with conventional treatment.

\section{Methods}

\section{Setting and participants}

Following the descriptive cross-sectional design, the study was conducted at oncology outpatient clinics (radiotherapy and/or chemotherapy) at National Cancer Center (NCC), the only specialized cancer center in Ulaanbaatar, Mongolia. The National Cancer Center in Ulaanbaatar has both inpatient and outpatient chemotherapy and radiotherapy units where approximately 1300 patients receive the treatment over a period of 6 months. However, for this study only patients attending the outpatient clinics of chemotherapy and radiotherapy were surveyed. Moreover, with the help of hospital staff it was ensured that no patient was surveyed for more than one time in case they visited the clinics again for followups during the study period.

\section{Survey instrument}

After a literature review, the survey instrument appropriate to local context was initially drafted in English and assessed by two experienced oncologists, a pharmacist and a researcher. The questionnaire was then modified according to the assessment, translated into the Mongolian language by a professional translator, and then it was pilot-tested. Translation accuracy of the survey questionnaire was validated by back-translation into English. After this, another pilot test was conducted with 20 cancer patients at different stages of treatment in order to refine the questionnaire and improve its clarity. The final questionnaire comprised four sections. The first section had five questions concerning the individual's health status, diagnosis, and whether they were currently receiving conventional cancer treatment. The second section consisted of 11 questions related to use of CAM. Questions on patterns of CAM, reasons for use, satisfaction with using CAM and source of information on CAM were only asked from respondents who reported using at least one modality of CAM. The third section contained four questions asking respondent's attitudes and beliefs toward CAM. The last section dealt with five questions showing the participant's age, gender, level of income, level of education and area of residence. Conventional cancer treatment, particularly chemotherapy and radiation, are known to cause a number of side effects [18]. After some literature review, a list of five common symptoms, which are routinely experienced by patients with cancer, was included in the survey instrument. All the respondents (CAM users and non-users) were asked to report the symptoms for which they would like to use CAM without a doctor's prescription.

\section{Study subjects}

The cancer patients attending the oncology outpatient clinic of the hospital from September 1, 2015 to February 28, 2016 were recruited into this study. The inclusion criteria were adult patients (over 20 years old) of either gender with a diagnosis of cancer, aware of their diagnosis of cancer, able to understand the questions, and willing to participate in the study. The ethical approval for this survey was obtained from the School of Medicine at Hanyang University, South Korea (HYI-15-111-2) and the Ministry of Health and Sports, Mongolia (No-05). Enrollment was voluntary and all patients gave written consent to participate in the study.

\section{Data collection}

All patients who met the inclusion criteria during the study period were invited to participate. Information about the research was given verbally to each respondent and consent was sought before the participation. Participants were informed that they could quit the survey anytime they wanted to. For interviewing cancer patients, three experienced interviewers were trained, who explained the CAM to the study participants administered the questionnaire. The patients were given the option either to fill out the questionnaire themselves or to verbally respond to the questions asked by the interviewers. In total, 504 patients agreed to participate in the survey. Of these, 22 were excluded due to an incomplete questionnaire; so the data of 482 participants were entered into the database for further analysis. A high response rate of 95.6\% shows the willingness of survey respondents to be helpful as they were ensured complete anonymity.

\section{Statistical analysis}

Respondents were categorized as CAM users or nonusers according to whether they used at least one modality of CAM for cancer-related outcomes since diagnosis. The collected data included sociodemographic and clinical characteristics (type of cancer, present medical treatment, and duration since diagnosis) and CAM use. Comparisons between categorical variables were executed using Pearson's Chi-square test or Fisher's exact test. Multivariate logistic regressions were employed for independent variables to evaluate significant factors that could predict use of CAM. P-values of $<0.05$ were considered statistically significant. All statistical analyses were done using Statistical Package for Social Sciences (SPSS) version 21.0 for Windows. 


\section{Results}

\section{Socio-demographic and clinical characteristics}

Sociodemographic and clinical characteristics of the survey participants are presented in Table 1 . Out of 482 respondents, the majority were females (63.9\%), below 55 years of age (59.5\%), from a rural area (66.4\%), had less than or equal to high school education (64.1\%) and had relatively low monthly household income $(\leq$ \$300US/ month) (57.1\%). The most frequent types of cancer included gastrointestinal (36.1\%), urogenital $(29 \%)$ and breast cancers $(15.6 \%)$. The majority of patients $(n=324$; $67.2 \%)$ were receiving chemotherapy at the time of study.

\section{Use of CAM and difference between users and non-users} Use of CAM to manage symptoms associated with cancer and its treatment was reported by $47.9 \%(n=231)$ of respondents. Half of users used CAM while receiving conventional cancer treatment. Survey participants more

Table 1 Respondent characteristics of CAM users and non-CAM users

\begin{tabular}{|c|c|c|c|c|}
\hline Variables & Total n (\%) 482 (100.0) & Non-CAM user n (\%) 251 (52.1) & CAM user n (\%) 231 (47.9) & $P$-value \\
\hline Gender & & & & 0.001 \\
\hline Male & $174(36.1)$ & $108(43)$ & $66(28.6)$ & \\
\hline Female & $308(63.9)$ & $143(57)$ & $165(71.4)$ & \\
\hline Age & & & & 0.007 \\
\hline$<55$ years & $287(59.5)$ & $135(53.8)$ & $152(65.8)$ & \\
\hline$>55$ years & $195(40.5)$ & $116(46.2)$ & 79 (34.2) & \\
\hline Mean age (SD) & $51.8\{12.5\}$ & $53.1\{12.5\}$ & $50.2\{12.4\}$ & $<0.012^{*}$ \\
\hline Residing area & & & & 0.792 \\
\hline Urban & $162(33.6)$ & $83(33.1)$ & $79(34.2)$ & \\
\hline Rural & $320(66.4)$ & $168(66.9)$ & $152(65.8)$ & \\
\hline Education level & & & & 0.012 \\
\hline No education & $4(0.8)$ & $3(1.2)$ & $1(0.4)$ & \\
\hline Primary education & $29(6)$ & $19(7.6)$ & $10(4.3)$ & \\
\hline Middle/high school & $281(58.3)$ & $157(62.5)$ & $124(53.7)$ & \\
\hline College/university & $168(34.9)$ & $72(28.7)$ & $96(41.6)$ & \\
\hline Household income & & & & 0.105 \\
\hline$<300$ & $275(57.1)$ & $152(60.6)$ & $123(53.2)$ & \\
\hline$>300$ & $207(42.9)$ & $99(39.4)$ & $108(46.8)$ & \\
\hline Self-perceived health status & & & & 0.757 \\
\hline Neither good nor poor & $281(58.3)$ & $148(59)$ & $133(57.6)$ & \\
\hline Good & $201(41.7)$ & $103(41)$ & $98(42.4)$ & \\
\hline Type of cancer & & & & 0.02 \\
\hline Breast & $75(15.6)$ & $32(12)$. & $43(18.6)$ & \\
\hline Gastrointestinal & $174(36.1)$ & $105(41.8)$ & $69(29.9)$ & \\
\hline Urogenital & $140(29)$ & $73(29.1)$ & $67(29)$ & \\
\hline Others & $93(19.3)$ & $41(16.4)$ & $52(22.5)$ & \\
\hline Time since diagnosis & & & & $<0.001$ \\
\hline $0-6$ months & $385(66)$ & $221(88)$ & $167(71)$ & \\
\hline More than 6 months & $97(34)$ & $30(12)$ & $64(29)$ & \\
\hline Conventional treatment & & & & 0.0019 \\
\hline Radiotherapy & $96(19.9)$ & $62(24.7)$ & $34(14.7)$ & \\
\hline Chemotherapy & $324(67.2)$ & $161(64.1)$ & $163(70.6)$ & \\
\hline Radiochemotherapy & $62(12.9)$ & $28(11.2)$ & $34(14.7)$ & \\
\hline Prior use of CAM & & & & $<0.001$ \\
\hline Yes & $232(48.1)$ & $91(36.2)$ & $141(61)$ & \\
\hline No & $250(51.9)$ & $160(63.7)$ & $90(39)$ & \\
\hline
\end{tabular}


likely to use CAM were female, younger, and had middle/high school education, were more recently diagnosed of cancer, had gastro-intestinal or urogenital cancer, were receiving active chemotherapy, and had used CAM before diagnosis of cancer (Table 1).

\section{Predictors of CAM use}

A logistic regression model was used to assess if any socio-demographic and clinical characteristics were independently associated with the decision to use CAM for cancer-related outcomes (Table 2). The multiple logistic regression model shows that CAM use was significantly associated with female gender (OR 1.749, 95\% CI 1.15$2.658, p=0.009$ ), younger age (OR 1.662, 95\% CI 1.1092.493, $p=0.014$ ), higher level of education (OR 1.798, CI $1.196-2.702, p=0.005$ ), shorter time since diagnosis (OR 2.963, 95\% CI 1.364-6.436, $p<0.006)$, and prior use of CAM (OR 3.027, 95\% CI 2.031-4.513, $p<0.001$ ).

\section{CAM modalities}

The frequency of leading CAM modalities along with perceived effectiveness reported by CAM users are listed in Table 3. Products of animal origin (150 of 231 users, $64.9 \%$ ) were the most popular modalities of CAM used for cancer-related outcomes followed by herbal medicine (32.9\%), mind-body therapies (29.4\%), dietary supplements (10.8\%), and Mongolian traditional medicine (2.2\%). Users of products of animal origin reported taking 18 different products while herbal medicine users reported using five different herbs. Of these products, tripe (37.2\%), wild animal products $(18.2 \%)$, rhubarb (18.2\%), milk bath (16.9\%), and dried foam from a camel's mouth (16.0\%) were most commonly used. Proportion of users who perceived CAM as helpful for the purposes they used for are also presented in Table 3.

Table 2 Logistic regression model: association of CAM use with various factors

\begin{tabular}{llllll}
\hline Variable & Category & OR & $95 \% \mathrm{Cl}$ & & $P$ value \\
\hline Gender & Male & 1.749 & 1.15 & 2.658 & 0.009 \\
& Female & & & & \\
Age & $\leq 55$ years & 1.662 & 1.109 & 2.493 & 0.014 \\
& $>55$ years & & & & \\
Education level & $\leq$ high school & 1.798 & 1.196 & 2.702 & 0.005 \\
& Post high school & & & & \\
Time since diagnosis & $\leq 6$ months & 2.963 & 1.364 & 6.436 & 0.006 \\
& $>6$ months & & & & \\
Prior use of CAM & Yes & 3.027 & 2.031 & 4.513 & $<0.001$ \\
& No & & & & \\
\hline
\end{tabular}

\section{Source of information}

As illustrated in Table 4, most CAM users obtained information about CAM modalities from other cancer patients (24.7\%), followed by family members (22.5\%), friends (19.0\%) and mass media and the internet (15.2\%). Health professionals including general practitioners and oncologists were least likely to recommend use of CAM (6.4\%).

\section{Reasons for using CAM}

Increasing chance of cure (41.6\%) was the most frequently reported reason for using CAM. Patients also associated the consumption of CAM with boosting the immune system (35.5\%). Other reasons for using CAM by patients with cancer referred to symptom relief (18.2\%) and others (11.3\%) (Table 4).

\section{CAM users' attitudes and beliefs}

Overall, about $65.8 \%$ of the CAM users agreed that use of CAM is generally safe, whilst $23.4 \%$ were "neutral" and $10.8 \%$ disagreed. Moreover, only $38.1 \%$ agreed that concurrent use of CAM and conventional treatment of cancer is safe, whereas $37.2 \%$ disagreed. Of the 231 users, only $29.0 \%$ discussed the concurrent use of CAM with their doctors. Most common reasons for nondisclosure were doctors did not ask (75.6\%) and it was not necessary for doctors to know (18.9\%) (Table 4).

\section{CAM use for managing of symptoms}

As shown in Table 5, the majority of patients indicated that they would consider CAM use for pain management (38.2\%), fatigue (27.0\%), constipation (26.3\%) and nausea and vomiting (21.6\%). Anxiety or depression (17.4\%) was least likely to cause use of CAM by patients with cancer.

\section{Discussion}

To our knowledge, the current findings are the first to report the prevalence and patterns of CAM use among Mongolian patients with cancer. It also described the patients' attitude and beliefs towards concurrent use of CAM and conventional treatment in oncology setting.

It is believed that Traditional Mongolian Medicine has derived many techniques and theories from the Traditional Tibetan Medicine. It also integrates some aspects of Indian Ayurveda and Traditional Chinese Medicine. In current study, a wide range modalities were included in CAM, and the results show that the prevalence of CAM use $(47.9 \%)$ is similar to a previous study in Japan [4], but higher than that reported in Europe [6], Australia [8], and South Korea [19]. This difference of CAM utilization rate between several studies could be most likely due to multiple factors such as culture, socioeconomic condition, and/or study methodology itself. Characteristics of CAM users found in this study were 
Table 3 Leading CAM modalities reported by cancer patients ${ }^{a}$

\begin{tabular}{llll}
\hline CAM modality & Name of products & $N-231(\%)$ & $N(\%)$ of users who believed the product helped \\
\hline Products of animal origin (64.9\%) & Tripe (goat, sheep etc.) & $86(37.2)$ & $58(67.4)$ \\
& Wild animal products & $42(18.2)$ & $29(69.0)$ \\
& Milk bath & $39(16.9)$ & $31(79.5)$ \\
& Dried foam from camel's mouth & $37(16.0)$ & $21(56.8)$ \\
& Mare's milk & $1(0.4)$ & $1(100.0)$ \\
Herbal medicine (32.9\%) & Rhubarb & $42(18.2)$ & $18(42.9)$ \\
& Celandine & $10(4.3)$ & $8(80.0)$ \\
& Gardenia & $8(3.5)$ & $4(50.0)$ \\
& Unknown complex herbal capsules or dragees & $7(3.0)$ & $4(57.1)$ \\
& Mushrooms & $9(3.9)$ & $6(66.7)$ \\
& Ginseng & $3(1.3)$ & $2(66.7)$ \\
Mind-body therapies (29.4\%) & Mantra & $46(19.9)$ & $36(78.3)$ \\
& Meditation/Yoga & $10(4.3)$ & $8(80.0)$ \\
& Massage & $5(2.2)$ & $4(80.0)$ \\
Bone setting & $3(1.3)$ & $3(100.0)$ \\
Vitamin/dietary supplements & $25(10.8)$ & $16(64.0)$ \\
Mongolian traditional medicine & $5(2.2)$ & $4(80.0)$ \\
Acupuncture & $2(0.9)$ & $1(50.0)$ \\
\hline
\end{tabular}

${ }^{\mathrm{a}}$ multiple choice question

in line with previous studies where female gender, younger age, higher level of education, prior use of CAM and shorter time since diagnosis were associated with CAM use $[20,21]$.

In evaluating types of CAM modalities used by cancer patients, we found that products of animal origin were by far most commonly used. This finding differs from past studies in which vitamins, minerals and herbs were found to be more popular than other types of therapy $[6,7]$. Some products of animal origin particularly, raw, fermented or processed dairy products are used as a part of everyday nutrition by many Mongolians. However, based on authors' understanding of the local culture, some modalities of animal origin were included in CAM because these products are also consumed as medicine. Moreover, in a textbook of Mongolian traditional medicine, Norovsambuu has described clinical indications of several products of animal origin and herbs for a number of diseases including cancer [22]. Additionally, clinical indications of some leading products of animal origin such as tripe have been traced in ancient Chinese dietary medicine texts $[23,24]$. According to these texts, tripe has many properties like strengthening the middle burner (spleen and stomach) and restoring qi (life force); thus it is useful for weak people or those who has deficiency of xue (blood) and qi (life force) [25, 26]. However, most of these modalities have gained popularity as CAM based on folk belief and have not yet been evaluated in clinical settings. Consequently, clinicians and in particular oncologists, might encounter unwanted effects and complications among their patients who use such modalities of CAM $[10,11]$.

We found that nearly half of the CAM users reported "increasing chance of cure", either directly or indirectly, as the main reason for using CAM. These results are consistent with previous studies [4, 9]; however, other studies that have indicated benefits other than cure (such as, to feel better, to reduce stress and to improve the quality of life) as the main reason for using CAM $[27,28]$. The majority of users believed that CAM was effective. However, it is difficult to say whether these improvements were related to use of CAM, since all patients received conventional cancer treatment at the same time. Other patients, family members and friends were a commonly reported source of information about CAM. This finding is in agreement with previous studies investigating the source of information of CAM among cancer patients $[6,29,30]$. Although the questionnaire used in the current study did not ask the patients why they used their social and lay network as a source of information, Verhoef et al. [31] suggested that it may be related to patients' feeling of connection with these people and thus they consider them as "trusted" source of health information.

Only about $15 \%$ of patients in our sample indicated that they would consider CAM use for anxiety and/or depression. This is inconsistent with what is found in previous studies in the US and South Korea, where patients were 
Table 4 CAM users' attitudes and beliefs

\begin{tabular}{|c|c|c|}
\hline Category & $N-231$ & $\%$ \\
\hline \multicolumn{3}{|l|}{ Source of CAM information } \\
\hline Other patients & 57 & 24.7 \\
\hline Family members & 52 & 22.5 \\
\hline Friends & 44 & 19.0 \\
\hline Mass media/internet & 35 & 15.2 \\
\hline Health professionals & 14 & 6.1 \\
\hline Others & 29 & 12.6 \\
\hline \multicolumn{3}{|l|}{ Reasons for using CAM ${ }^{a}$} \\
\hline To cure the cancer & 96 & 41.6 \\
\hline To boost the immune system & 82 & 35.5 \\
\hline Relief from symptoms & 42 & 18.2 \\
\hline Others & 26 & 11.3 \\
\hline \multicolumn{3}{|l|}{ Use of CAM is safe } \\
\hline Agree & 152 & 65.8 \\
\hline Neutral & 54 & 23.4 \\
\hline Disagree & 25 & 10.8 \\
\hline \multicolumn{3}{|c|}{ CAM use and conventional cancer treatment is safe } \\
\hline Agree & 88 & 38.1 \\
\hline Neutral & 57 & 24.7 \\
\hline Disagree & 86 & 37.2 \\
\hline \multicolumn{3}{|l|}{ Disclosure of CAM use to doctor } \\
\hline Yes & 67 & 29.0 \\
\hline No & 164 & 71.0 \\
\hline \multicolumn{3}{|l|}{ Reason for nondisclosure ( $N$ - 164) } \\
\hline Doctor did not ask & 124 & 75.6 \\
\hline Not necessary & 31 & 18.9 \\
\hline Fear that doctor would disapprove & 9 & 5.5 \\
\hline
\end{tabular}

using multiple CAM modalities to manage depression and anxiety [32-34]. Such an inconsistency could be related to the variety of CAM modalities used by patients with cancer. For instance, there is evidence that patients used yoga therapy to manage anxiety, depression and other emotional symptoms [34-36]. However, yoga therapy was not quite popular among sample of this study.

Table 5 Consideration of CAM use for symptom management ${ }^{a}$

\begin{tabular}{llll}
\hline Category & Total $n=482$ & CAM user $n=231$ & Non-user $n=251$ \\
\hline Pain management & $184(38.2)$ & $109(47.2)$ & $75(29.9)$ \\
Fatigue & $130(27.0)$ & $68(29.4)$ & $62(24.7)$ \\
Constipation & $127(26.3)$ & $70(30.3)$ & $57(22.7)$ \\
Nausea/vomiting & $104(21.6)$ & $50(21.6)$ & $54(21.5)$ \\
Anxiety/depression & $84(17.4)$ & $34(14.7)$ & $50(19.9)$ \\
\hline $\begin{array}{l}\text { N (\%) } \\
\text { amultiple choice question }\end{array}$ & &
\end{tabular}

We also found that most of the CAM users believed CAM to be safe, however, there were split responses when asked about the concurrent use of CAM and conventional treatment. However, all of the CAM users were receiving conventional treatment for cancer. Such results could be due to the social desirability bias, as during the survey the patients were attending a cancer hospital for conventional treatment and few of them might have been afraid to give response in support of CAM. Similar to past studies, a relatively small proportion of CAM users made their doctors aware of their decision to use CAM $[3,5]$. This could be dangerous, specifically in the area of oncology, where treatment methods and procedures are becoming more and more advanced. The risk of interaction between patients' use of CAM by their own decision and conventional treatment might jeopardize their life, as evidence suggests that consumption of CAM can have negative effects when used concurrently with conventional radiotherapy and/or chemotherapy $[10,11]$. Therefore, we recommend clinicians to be more aware of their patients' health care behavior, and more effective communication approaches should be adopted to ensure safe use of CAM especially during conventional cancer treatment.

\section{Limitations}

There are a few limitations of our study. First, as some of the questions investigated past events, so recall bias might have influenced the results. Second, this study might have overestimated the use of CAM among cancer patients as a result of the voluntary response bias. Patients who had an interest in CAM or were using CAM modalities may have been more likely to participate in this study. Moreover, there was a low response from men with cancer and thus the views expressed by the study participants may not fully reflect those of the whole cancer population. As these are the first findings to report use of CAM in Mongolia, a broad range of CAM modalities were included in the survey. The authors are working on another research where Traditional Mongolian Methods of CAM such as bone art and balneotherapy will be reported in near future. Despite these limitations, this study sheds light on different but important aspects of CAM use among Mongolian patients with cancer.

\section{Conclusions}

CAM appears to be widely accepted by patients with cancer in Mongolia. Health care providers should take the initiative to ask whether patients are using any CAM, so they can provide evidence-based consultation regarding the appropriateness of using CAM during conventional cancer treatment. Clinicians in those ethnically and culturally diverse countries where Mongolians are ethnic minorities should be aware of the fact that many 
Mongolian cancer patients use modalities of CAM for cancer-related outcomes. The findings support the urgent need for further in-depth study into commonly used CAM products and their potential effects on health of cancer population in Mongolia. High prevalence of CAM use among patients with cancer in our study warrants further studies in other countries of this region.

\section{Abbreviation}

CAM: Complementary and alternative medicine

\section{Acknowledgements}

The study was supported by Global Korea Scholarship. We are also grateful to all the patients who took part in this study.

\section{Funding}

None.

\section{Availability of data and materials}

The data will be accessible by contacting the corresponding author of this study.

\section{Authors' contributions}

$\mathrm{JH}, \mathrm{OB}$ and $\mathrm{DW}$ were responsible to the study concept and design. DW, JH, and $\mathrm{OB}$ analyzed the data and drafted the manuscript. $\mathrm{OB}$ and $\mathrm{DW}$ contributed in the designing of data collection tools and data collection. JH, DW, SJ and MA and OB critically reviewed the manuscript and contributed intellectual content. All authors read and approved the final manuscript.

\section{Competing interests}

The authors declare that they have no competing interests.

\section{Consent for publication}

Not applicable.

\section{Ethics approval and consent to participate}

Ethical approval for the study was acquired from Institutional Review Board on Human Subjects Research and Ethics Committees, Hanyang University (HYI-15-111-2) and the Ministry of Health and Sports, Mongolia (No-05). All study participants gave written consent before taking part in the study.

\section{Author details}

'Department of Global Health and Development, Graduate school, Hanyang University, Seoul, South Korea. ${ }^{2}$ Institute of Health Services Management, Hanyang University College of Medicine, Seoul, South Korea. ${ }^{3}$ Department of Obstetrics and Gynecology, Hanyang University College of Medicine, Seoul, South Korea. ${ }^{4}$ Department of Preventive Medicine, Hanyang University College of Medicine, Seoul, South Korea. ${ }^{5}$ Department of Preventive Medicine, Hanyang University College of Medicine, 222 Wangsimni-ro, Seongdong-gu, Seoul 133-791, South Korea.

Received: 30 June 2016 Accepted: 11 January 2017

Published online: 19 January 2017

\section{References}

1. Ernst E. The prevalence of complementary/alternative medicine in cancer. Cancer. 1998:83(4):777-82.

2. Eisenberg DM, Davis RB, Ettner SL, Appel S, Wilkey S, Van Rompay M, Kessler RC. Trends in alternative medicine use in the United States, 1990-1997: results of a follow-up national survey. Jama. 1998;280(18):1569-75.

3. Eisenberg DM, Kessler RC, Van Rompay MI, Kaptchuk TJ, Wilkey SA, Appel S, Davis RB. Perceptions about complementary therapies relative to conventional therapies among adults who use both: results from a national survey. Ann Intern Med. 2001;135(5):344-51.

4. Hyodo I, Amano N, Eguchi K, Narabayashi M, Imanishi J, Hirai M, Nakano T, Takashima S. Nationwide survey on complementary and alternative medicine in cancer patients in Japan. J Clin Oncol. 2005;23(12):2645-54.
5. Davis EL, Oh B, Butow PN, Mullan BA, Clarke S. Cancer patient disclosure and patient-doctor communication of complementary and alternative medicine use: a systematic review. Oncologist. 2012;17(11):1475-81.

6. Molassiotis A, Fernadez-Ortega P, Pud D, Ozden G, Scott JA, Panteli V, Margulies A, Browall M, Magri M, Selvekerova S. Use of complementary and alternative medicine in cancer patients: a European survey. Ann Oncol. 2005;16(4):655-63.

7. Anderson JG, Taylor AG. Use of complementary therapies for cancer symptom management: results of the 2007 National Health Interview Survey. J Altern Complement Med. 2012;18(3):235-41.

8. Oh B, Butow P, Mullan B, Beale P, Pavlakis N, Rosenthal D, Clarke S. The use and perceived benefits resulting from the use of complementary and alternative medicine by cancer patients in Australia. Asia Pac J Clin Oncol. 2010;6(4):342-9.

9. Cui Y, Shu X-O, Gao Y, Wen W, Ruan Z-X, Jin F, Zheng W. Use of complementary and alternative medicine by Chinese women with breast cancer. Breast Cancer Res Treat. 2004;85(3):263-70.

10. Bairati I, Meyer F, Gélinas M, Fortin A, Nabid A, Brochet F, Mercier J-P, Têtu B, Harel F, Abdous B. Randomized trial of antioxidant vitamins to prevent acute adverse effects of radiation therapy in head and neck cancer patients. J Clin Oncol. 2005;23(24):5805-13.

11. Seely D, Oneschuk D. Interactions of natural health products with biomedical cancer treatments. Curr Oncol. 2008:15 Suppl 2:\$81-6.

12. Ko RJ. A US perspective on the adverse reactions from traditional Chinese medicines. J Chin Med Assoc. 2004;67(3):109-16.

13. Bernstein J, Stibich M, LeBaron S. Use of traditional medicine in Mongolia: a survey. Complement Ther Med. 2002;10(1):42-5.

14. Stickley A, Koyanagi A, Richardson E, Roberts B, Balabanova D, McKee M. Prevalence and factors associated with the use of alternative (folk) medicine practitioners in 8 countries of the former Soviet Union. BMC Complement Altern Med. 2013;13(1):1.

15. Ben-Arye E, Shturman E, Klein A, Frenkel M. Attitudes of immigrants from the former Soviet Union towards complementary medicine. Harefuah. 2007; 146(8):584. $-588,648,647$.

16. Hwang JH, Han DW, Yoo EK, Kim W-Y. The utilisation of Complementary and Alternative Medicine (CAM) among ethnic minorities in South Korea. BMC Complement Altern Med. 2014;14(1):1.

17. Ferlay J, Shin HR, Bray F, Forman D, Mathers C, Parkin DM. Estimates of worldwide burden of cancer in 2008: GLOBOCAN 2008. Int J Cancer. 2010; 127(12):2893-917.

18. So WK, Marsh G, Ling W, Leung F, Lo JC, Yeung M, Li GK. The symptom cluster of fatigue, pain, anxiety, and depression and the effect on the quality of life of women receiving treatment for breast cancer: a multicenter study. Oncol Nurs Forum. 2009;36:E205-14.

19. Shin J-Y, Kim SY, Park B, Park J-H, Choi JY, Seo HG, Park J-H. Predictors of complementary and alternative medicine use in cancer care: results of a nationwide multicenter survey in Korea. Evid Based Complement Alternat Med. 2012;2012:212386.

20. Choi K-H, Park J-H, Park S-M. Cancer patients' informational needs on health promotion and related factors: a multi-institutional, cross-sectional study in Korea. Support Care Cancer. 2011;19(10):1495-504.

21. Corner J, Yardley J, Maher E, Roffe L, Young T, Maslin-Prothero S, Gwilliam C, Haviland J, Lewith G. Patterns of complementary and alternative medicine use among patients undergoing cancer treatment. Eur J Cancer Care (Engl). 2009:18(3):271-9.

22. Norovsambuu. Traditional Medicine. Ulaanbaatar: Soyombo Printing Company; 2005

23. Laudan R. A Soup for the Qan: Chinese Dietary Medicine of the Mongol Era as Seen in Hu Szu-Hui's Yin-shan Cheng-Yao (review). J World Hist. 2003;14(4):563-6.

24. Ning C. Interesting discussion on Jin (jin zuo qu tan). Jiangsu Condiment Subsidiary Food. 1996;1:26-7.

25. Li L, Wang CC, Zhou SY, Li J, Song Z, Hou FM. Research progress on processing technology of tripe. In: Advanced Materials Research: 2012: Trans Tech Publ. 2012. p. 994-9.

26. Ouyang J. Niu nian hua niu zuo. Fam Med. 2009;1:50-4.

27. Sparber A, Wootton JC. Surveys of complementary and alternative medicine: Part II. Use of alternative and complementary cancer therapies. J Altern Complement Med. 2001;7(3):281-7.

28. Naing A, Stephen SK, Frenkel M, Chandhasin C, Hong DS, Lei X, Falchook G, Wheler JJ, Fu S, Kurzrock R. Prevalence of complementary medicine use in a phase 1 clinical trials program. Cancer. 2011;117(22):5142-50. 
29. Shih V, Chiang J, Chan A. Complementary and alternative medicine (CAM) usage in Singaporean adult cancer patients. Ann Oncol. 2009;20(4):752-7.

30. Evans M, Shaw A, Thompson EA, Falk S, Turton P, Thompson T, Sharp D. Decisions to use complementary and alternative medicine (CAM) by male cancer patients: information-seeking roles and types of evidence used. BMC Complement Altern Med. 2007;7(1):25.

31. Verhoef MJ, Mulkins A, Boon H. Integrative health care: how can we determine whether patients benefit? J Altern Complement Med. 2005 11(supplement 1):s-57-65.

32. Montazeri A, Sajadian A, Ebrahimi M, Akbari ME. Depression and the use of complementary medicine among breast cancer patients. Support Care Cancer. 2005;13(5):339-42.

33. Eschiti VS. Complementary and alternative modalities used by women with female-specific cancers. Holist Nurs Pract. 2008;22(3):127-38.

34. Hwang JH, Kim W-Y, Ahmed M, Choi S, Kim J, Han DW. The use of complementary and alternative medicine by Korean breast cancer women: is It associated with severity of symptoms? Evid Based Complement Alternat Med. 2015;2015:182475.

35. Rao MR, Raghuram N, Nagendra H, Gopinath K, Srinath B, Diwakar RB, Patil S, Bilimagga SR, Rao N, Varambally S. Anxiolytic effects of a yoga program in early breast cancer patients undergoing conventional treatment: a randomized controlled trial. Complement Ther Med. 2009:17(1):1-8.

36. Danhauer SC, Mihalko SL, Russell GB, Campbell CR, Felder L, Daley K, Levine EA. Restorative yoga for women with breast cancer: findings from a randomized pilot study. Psycho-Oncology. 2009;18(4):360-8.

\section{Submit your next manuscript to BioMed Central and we will help you at every step:}

- We accept pre-submission inquiries

- Our selector tool helps you to find the most relevant journal

- We provide round the clock customer support

- Convenient online submission

- Thorough peer review

- Inclusion in PubMed and all major indexing services

- Maximum visibility for your research

Submit your manuscript at www.biomedcentral.com/submit 